\title{
Fluid resuscitation-related coagulation impairment in a porcine hemorrhagic shock model
}

\author{
Alexander Ziebart ${ }^{\text {Corresp., }}{ }^{1}$, Robert Ruemmler ${ }^{1}$, Christian Möllmann ${ }^{1}$, Jens Kamuf ${ }^{1}$, Andreas Garcia-Bardon ${ }^{1}$, Serge \\ Thal $^{1}$, Erik K. Hartmann ${ }^{1}$ \\ 1 Department of Anesthesiology, Medical Centre of the Johannes Gutenberg-University, Mainz, Germany \\ Corresponding Author: Alexander Ziebart \\ Email address: alexander.ziebart@unimedizin-mainz.de
}

Background: Fast and effective treatment of hemorrhagic shock is one of the most important preclinical trauma care tasks e.g. in combat casualties in avoiding severe end-organ damage or death. In scenarios without immediate availability of blood products, alternate regimens of fluid resuscitation represent the only possibility of maintaining sufficient circulation and regaining adequate end-organ oxygen supply. However, the fluid choice alone may affect the extent of the bleeding by interfering with coagulation pathways. This study investigates the impact of hydroxyethyl starch (HES), gelatine-polysuccinate (GP) and balanced electrolyte solution (BES) as commonly used agents for fluid resuscitation on coagulation using a porcine hemorrhagic shock model.

Methods: Following approval by the State and Institutional Animal Care Committee, life-threatening hemorrhagic shock was induced via arterial blood withdrawal in 24 anesthetized pigs. Isovolumetric fluid resuscitation with either HES, GP or BES ( $n=3 \times 8)$ was performed to compensate for the blood loss. Over four hours, hemodynamics, laboratory parameters and rotational thromboelastometry-derived coagulation were analyzed. As secondary endpoint the porcine values were compared to human blood.

Results: All the agents used for fluid resuscitation significantly affected coagulation. We measured a restriction of laboratory parameters, clot development and clot firmness, particularly in HES- and GPtreated animals. Hemoglobin content dropped in all groups but showed a more pronounced decline in colloid-treated pigs. This effect was not maintained over the four-hour monitoring period.

Conclusion: HES, GP, and BEL sufficiently stabilized the macrocirculation, but significantly affected coagulation. These effects were most pronounced after colloid and particularly HES administration. Despite suitability for rapid hemodynamic stabilization, colloids have to be chosen with caution, because their molecular properties may affect coagulation directly and as a consequence of pronounced hemodilution. Our comparison of porcine and human coagulation showed increased coagulation activity in pig blood. 
1 Fluid resuscitation-related coagulation impairment in a porcine hemorrhagic

4 Alexander Ziebart $^{1}$ M.D.

5 Robert Ruemmler ${ }^{1}$ M.D.

6 Christian Möllmann ${ }^{1}$ M.D.

7 Jens Kamuf ${ }^{1}$ M.D.

8 Andreas Garcia-Bardon ${ }^{1}$ M.D.

9 Serge C. Thal ${ }^{1}$ M.D., Ph.D.

10 Erik K. Hartmann ${ }^{1}$ M.D., Ph.D.

11

12

13

\section{Corresponding author:}

Dr. med. Alexander Ziebart, DESA

Department of Anesthesiology

Langenbeckstraße 1

55131 Mainz, Germany

$\underline{\text { 00496131-179817 }}$

6

alexander.ziebart@unimedizin-mainz.de robert.ruemmler@email.de

cmoellma@uni-mainz.de

kamuf@uni-mainz.de

a.garciabardon@uni-mainz.de

thal@uni-mainz.de

hartmane@uni-mainz.de

Medical Centre of the Johannes Gutenberg University

alexander.ziebart@unimedizin-mainz.de

\section{Langenbeckstr. 1, 55131 Mainz, Germany}




\section{Abstract:}

37 Background: Fast and effective treatment of hemorrhagic shock is one of the most important 38 preclinical trauma care tasks e.g. in combat casualties in avoiding severe end-organ damage or death. In scenarios without immediate availability of blood products, alternate regimens of fluid resuscitation represent the only possibility of maintaining sufficient circulation and regaining adequate end-organ oxygen supply. However, the fluid choice alone may affect the extent of the bleeding by interfering with coagulation pathways. This study investigates the impact of hydroxyethyl starch (HES), gelatine-polysuccinate (GP) and balanced electrolyte solution (BES) as commonly used agents for fluid resuscitation on coagulation using a porcine hemorrhagic shock model.

Methods: Following approval by the State and Institutional Animal Care Committee, lifethreatening hemorrhagic shock was induced via arterial blood withdrawal in 24 anesthetized pigs. Isovolumetric fluid resuscitation with either HES, GP or BES $(n=3 \times 8)$ was performed to compensate for the blood loss. Over four hours, hemodynamics, laboratory parameters and rotational thromboelastometry-derived coagulation were analyzed. As secondary endpoint the porcine values were compared to human blood.

Results: All the agents used for fluid resuscitation significantly affected coagulation. We measured a restriction of laboratory parameters, clot development and clot firmness, particularly in HES- and GP-treated animals. Hemoglobin content dropped in all groups but showed a more pronounced decline in colloid-treated pigs. This effect was not maintained over the four-hour monitoring period.

Conclusion: HES, GP, and BEL sufficiently stabilized the macrocirculation, but significantly affected coagulation. These effects were most pronounced after colloid and particularly HES administration. Despite suitability for rapid hemodynamic stabilization, colloids have to be chosen with caution, because their molecular properties may affect coagulation directly and as a 
64 consequence of pronounced hemodilution. Our comparison of porcine and human coagulation

65 showed increased coagulation activity in pig blood.

\section{Background:}

Massive blood loss as a hemorrhagic shock causes requires resolute and efficient action to prevent severe injury or death. As a factor in $15 \%$ of all fatal injuries, it is one of the most challenging issues in prehospital and early clinical scenarios $(1,2)$. The instability that results from massive blood loss induces an undersupply of oxygen and can cause irreversible organ failure $(3,4)$. To combat this problem, different regimens and guidelines focusing on fluid resuscitation have been established $(5,6)$. For years, colloids and especially hydroxyethyl starch (HES) have been indispensable for nearly all forms of shock resulting from relative or absolute hypovolemia. Their efficacy relies on macromolecule-related increases in oncotic pressure and decreased extravasation. Crystalloids, however, act only temporarily due to a free volume-specific shift into the extravascular space (7). Several clinical studies have questioned the safety of HES in the treatment of critical ill patients (8-10). Side effects such as increased risk of acute kidney injury, which requires renal replacement therapy and can even lead to mortality, have challenged the role of HES in the intensive care unit (11-14). Other detrimental effects of HES include increased perioperative blood loss and coagulopathy. Some studies, however still regard HES administration as reliable option, particularly in isolated, manageable bleeding scenarios and patient without risk constellation for acute kidney injury, which has led to controversial discussions $(15,16)$. In the past, the European Medicines Agency (EMA) recommended avoiding HES and prohibited its use in patients with severe sepsis or burn injuries (6). In 2018 and 2019, however, the EMA repermitted administration of HES for the management of acute blood loss-induced hypovolemia while pointing out several contraindications, including sepsis, severe coagulopathy and renal impairment or replacement therapy $(6,17)$. Nevertheless, these recommendations are undermined by lack of alternative solutions and clinical scenarios that represent a grey zone between defined indications and prohibitions. Gelatine-polysuccinate (GP) represents an alternative but less 
93 frequently applied colloid based on bovine collagen. Apart from its shorter intravascular 94 persistence, GP appears to be comparable to modern HES 130/0.4 (18, 19). Interestingly, 95 knowledge of the disadvantages and advantages of GP is limited (20-23), with the exception of a 96 higher risk of anaphylaxis compared to other colloids $(24,25)$. Bleeding control is a crucial task 97 during hemorrhagic shock and requires sufficient coagulation maintenance. Though indicated in 98 blood loss-related hypervolemia, HES bears the risk of coagulation impairment. (26-31). 99 Comparisons between HES and GP have shown similar detrimental effects, but only few studies 100 have investigated these effects during hemorrhagic shock (32-34).

101 Our aim was to explore the influence of HES and GP on coagulation with a focus on point-of-care 102 rotational thromboelastometry (ROTEM), which enables to fibrin polymerization analysis, clot 103 firmness and formation, platelet function and fibrinolysis through different assays (27). 104 Viscoelastic point-of-care methods are explicitly discussed in the European guidelines for the 105 management of traumatic and perioperative bleeding $(6,35)$ and are an important instrument in 106 early goal-directed coagulation therapy (36). We hypothesized that comparable amounts of HES 107 and GP would impair the coagulation cascade more so than balanced electrolyte solution (BES) in 108 a pig model simulating a preclinical hemorrhagic shock scenario.

\section{Methods}

111 This study was approved by the State and Institutional Animal Care Committee 112 (Landesuntersuchungsamt Rheinland-Pfalz, Koblenz, Germany; Chairperson: Dr Silvia Eisch113 Wolf; reference number: 23 177-07/G 15-1-092; 01/2016) in accordance with the ARRIVE

114 guidelines. This study represents an independent sub-project and complementary hypothesis of a 115 research project that investigates the cerebral effects of solutions for fluid resuscitation and did not 116 increase the overall number of animal experiments within this project. We included 24 juvenile 117 male pigs (sus scrofa domestica; mean weight $28 \pm 2 \mathrm{~kg}$; age: 8-12 weeks) in a prospective 118 randomized animal experiment.

Anesthesia and instrumentation

121 The anesthesia, instrumentation and shock induction were performed as previously described (37,

122 38). The animals stayed in their known environment for as long as possible to minimize stress, and 123 breeder controlled environmental conditions. The animals were sedated via intramuscular 
124 injections of ketamine $(8 \mathrm{mg} / \mathrm{kg})$ and midazolam $(0.2 \mathrm{mg} / \mathrm{kg})$ to minimize their stress during 125 transport. Fentanyl (4 $\mu \mathrm{g} / \mathrm{kg})$, propofol $(4 \mathrm{mg} / \mathrm{kg})$ and atracurium $(0.5 \mathrm{mg} / \mathrm{kg})$ were injected 126 intravenously via an ear-vein for general anesthesia and endotracheal intubation. Continuous 127 infusion of fentanyl (0.1-0.2 mg/kg/h) and propofol (8-12 mg/kg/h) maintained the anesthesia. 128 During the experiment, the animals were held under general anesthesia by means of continuous 129 propofol (8-12 mg/kg/h) and fentanyl (0.1-0.2 mg/kg/h) and ventilated in the following volume130 controlled mode (Evita 2, Draeger, Lübeck, Germany): positive end-expiratory pressure of 5 $131 \mathrm{cmH}_{2} \mathrm{O}$, a tidal volume of $8 \mathrm{ml} / \mathrm{kg}$, fraction of inspired oxygen of 0.4 , an inspiration to expiration 132 ratio of 1:2 and a variable respiration rate to achieve end-tidal $\mathrm{CO}_{2}<6 \mathrm{kPa}$.

133 Four femoral vascular catheters were placed using ultrasound guidance as follows: central venous 134 line (drug administration and thermodilution-related cold saline application, left femoral vein), 135 pulse contour cardiac output system (PiCCO, Pulsion Medical Systems, Germany, right femoral 136 artery), arterial line (blood withdrawal for shock model, left femoral artery) and large-bore venous 137 introducer (fluid resuscitation, right femoral vein). Hemodynamic and spirometric parameters 138 were constantly measured and recorded (LabVIEW, AD-Instruments, Sydney, Australia).

\section{Experimental design}

141 Instrumentation was performed, followed by 30 minutes of consolidation and baseline 142 documentation. Hemorrhagic shock was induced via arterial blood withdrawal (35-40 ml $/ \mathrm{kg})$ over

14315 minutes until mean arterial pressure $(<45 \mathrm{mmHg})$ and cardiac index $(<40 \%$ of the baseline 144 value) decreased (38). Figure 1 displays a short summary of this protocol.

145 Thirty minutes after the shock induction, the animals were randomized and treated according to a 146 group-specific fluid resuscitation regime and adjusted, according to the volume of removed blood, 147 as follows: GP (Gelafundin iso 4\%, B. Braun, Germany; $\mathrm{n}=8$ ) HES 130/0.4 (Volulyte 6\%, Fresenius Kabi AG, Germany; $\mathrm{n}=8$ )

153 No specific cardio-circulatory parameters influenced this approach. No further fluids or 154 catecholamine were administered other than a permanent BES infusion $(5 \mathrm{ml} / \mathrm{kg} / \mathrm{h})$. At the 
155 baseline, following fluid resuscitation and at the end of the experiment (baseline, $0 \mathrm{~h}$ and $4 \mathrm{~h}$ ), 156 blood was withdrawn for coagulation and laboratory analysis into standard test tubes. After four

157 hours of monitoring, the animals were killed during deep general anesthesia via central venous 158 administration of propofol and potassium chloride.

\section{Laboratory assessment}

161 Blood samples were collected at the baseline, following fluid resuscitation $(0 \mathrm{~h})$ and after four 162 hours of observation $(4 \mathrm{~h})$. The blood was stored in tubes with $0.14 \mathrm{ml}$ citrate solution (S163 Monovette $^{\circledR}$, Sarstedt, Nuembrecht, Germany). Laboratory blood tests, including partial 164 thromboplastin time (PTT), prothrombin time (PT), fibrinogen, platelet count, hemoglobin content and hematocrit, were used to analyze standard coagulation and blood parameters.

Rotational thromboelastometry

Rotational thromboelastometry (ROTEM ${ }^{\circledR}$ delta; TEM International GmbH, Munich, Germany) analyses were performed according to operation instructions. Thromboelastometry was able to detect changes in the viscoelastic characteristics of a citrate blood clot. The blood samples were mixed with specific reagents to allow for analysis of coagulation properties through the following

172 five tests: EXTEM, which investigates the tissue factor pathway (extrinsic); INTEM, which 173 determines the contact activation pathway (intrinsic); HEPTEM, which analyses heparin-induced 174 effects in comparison to INTEM; FIBTEM, which examines fibrinogen deficiency or restricted 175 fibrin polymerization in clots through the addition of cytochalasin $\mathrm{D}$ to inhibit platelet contribution; and APTEM, which uses aprotinin to analyze fibrinolysis. We performed all tests excluding HEPTEM, as no heparin was provided in the study protocol. To validate the measured values, we compared the baseline parameters with human references (39). Thromboelastometry analyses depict three phases of coagulation: clot formation (clotting time $=\mathrm{CT}$, time until clot starts to form; clot formation time $=$ CFT, time between CT and an amplitude of $20 \mathrm{~mm}$ clot firmness; alpha-angle $=$ alpha, angle between 0 and $2 \mathrm{~mm}$ of amplitude), clot firmness (A10 and A20, amplitude of clot firmness at 10 and 20 minutes; maximum clot firmness $=\mathrm{MCF}$, the absolute

183 highest amplitude of the curve) and lysis (maximum lysis = ML, maximum percentage loss of clot 184 strength compare to MCF) $(40,41)$. 


\section{Statistics}

187 We displayed the data in terms of mean and standard deviation (SD). The intergroup effects were analyzed using two-way analysis of variance (ANOVA). The Student-Newman-Keuls method was used for pairwise multiple comparison corrections. $\mathrm{P}$ values lower than $5 \%$ were considered significant. The statistical analysis was performed utilizing software package SigmaPlot 12.5

191 (Systat Software, USA). The porcine reference values were displayed as confidence intervals of a 192 confidence level of $95 \%$.

\section{Results:}

195 Comparable amounts of blood were withdrawn $(33 \pm 5 \mathrm{ml} / \mathrm{kg})$ for shock induction from all three 196 groups. Arterial blood pressure $(58 \pm 11 \%)$ and cardiac index $(50 \pm 12 \%)$ significantly decreased

197 in a shock-like fashion versus the baseline (each $\mathrm{p}<0.01$ ) (Table 1). The amounts of fluid 198 administered were also comparable.

199 In the HES and BES groups, a survival rate of $100 \%$ was achieved. In the GP group, one animal 200 died during a tachyarrhythmia episode one hour after the fluid resuscitation. The different infusion 201 regimens led to adequate hemodynamic stabilization in all groups. The cardiac index increase was 202 significantly greater following colloid infusion. After four hours, all values returned to the baseline 203 level, with the exception of heart rate in the BES group (Table 1). Immediately following shock 204 induction, the hemoglobin content was relatively unaltered; however, it significantly decreased 205 throughout fluid resuscitation, with a pronounced decrease in the colloid groups (each $\mathrm{p}<0.01$ ). 206 Fibrinogen, PT and PTT became considerably impaired in the colloid groups, whereas the BES 207 group was only affected to a minor extent (Table 1 and Figure 2).

208 The rotational thromboelastometry data showed no intergroup differences at the baseline. 209 Parameters concerning the temporal sequence (CT, CFT, alpha) as well as clot firmness (A10, 210 A20, MCF) were significantly impaired following administration of GP and HES, particularly in 211 EXTEM but also in INTEM. HES exerted the most detrimental effects, followed by GP. The BES 212 group varied significantly from the baseline, as-well, but were still higher compared to the colloid 213 groups (Figure 3-4). Similar to EXTEM significant impairment of FIBTEM and APTEM in the 214 colloid groups was observed (Figure 5-6). Regrettably, the FIBTEM clotting time in the GP and 215 HES groups were indeterminable due to technical errors. 
216 All rotational thromboelastometry-derived parameters recovered over the four hours in all groups,

217 but the extent of recovery differed between the different regimes. In both EXTEM and APTEM,

218 CT and CFT were most prolonged through HES administration compared to the baseline. and to

219 the other groups. CFT returned to the baseline level only in the BES group (Figures 3\&6).

220 Amplitude and MCF were restricted in all groups but nearly reached the baseline level in the BES-

221 treated animals (Figures 3-4). INTEM results were not as pronounced as the EXTEM, FIBTEM

222 and APTEM results. We observed no restrictions in ML and did not detect any signs of

223 hyperfibrinolysis in any of the groups (Figures 3-6).

224 Our comparison of porcine and human coagulation showed increased coagulation activity in pig

225 blood. This effect could be observed in all parameters and involved decreased clotting times and

226 increased amplitudes (Table 2).

227

\section{Discussion:}

229 This study investigated the influence of HES, GP and BES on coagulation during early 230 hemorrhagic shock in a pig model, with a focus on rotational thromboelastometry. Accordingly, 231 we found an impaired coagulatory activity that concerns temporal kinetics as well as clot firmness 232 as a consequence of fluid resuscitation in all groups, but with the most deleterious effects through 233 HES administration followed by GP. We simulated a frequent preclinical or clinical blood loss 234 scenario with subsequent bleeding control (i.e. during surgery). Shock was induced by defined 235 blood loss in combination with hemodynamic deterioration. If untreated, this model leads to 236 cardio-circulatory failure and death in $66 \%$ of the animals within two hours $(38,42)$. In the scenario 237 sufficient and quick action is necessary, and ongoing fluid therapy will not stop immediately after 238 bleeding control. Hemodynamic values were allowed to fall below the acceptable thresholds of 239 permissive hypotension (6) Isovolemic amounts of fluids were applied using a 1:1 replacement 240 regime. The chosen group size was adjusted on account of comparable large animal studies, that 241 also focused on hemorrhagic shock or cardiorespiratory effects $(37,43)$. The scenario concentrated 242 on rapid stabilization to avoid the undersupply of oxygen to the vital organs and did not stop 243 immediately after the bleeding was controlled.

244 Sufficient hemodynamic recovery through fluid resuscitation was registered for all three regimens.

245 In the colloid groups particularly, the baseline level was surpassed. After four hours, we did not 246 detect any significant intergroup differences, with the exception of heart rate, which remained 
247 increased in the GP and BES groups. These results were expected due to the high effectivity of 248 colloids in increasing osmotic pressure leading to increased intravascular volume. A ratio of 1:1.5 249 between colloids and crystalloids would theoretically achieve similar hemodynamics but would 250 not have simulated a realistic clinical scenario (11). As expected, we observed significantly lower 251 hemoglobin content following the HES and GP administration, a sign of hemodilution. 252 Hemodilution partially explains the impaired coagulation in the laboratory parameters and 253 thromboelastometry results. Conventional coagulation parameters, clot formatting and firmness 254 decreased in all groups, with the highest restriction following HES administration, then GP. These 255 effects were more expressed in the extrinsic pathway, fibrinogen content and platelet count. 256 Additionally, we compared our porcine baseline values with published human reference values; 257 the porcine coagulation activity seemed to be higher than that of humans. This can especially be 258 seen in the decreased clotting and clot formatting time and the pronounced clot firmness among 259 the porcine specimens. The related results in FIBTEM still after four hours can be explain by a 260 lack of fibrinogen that is not displayed into the conventional coagulation parameters. These 261 findings correspond with results from other studies in which porcine hypercoagulation was 262 described $(44,45)$. These findings must be considered when interpreting the results in order for 263 the right conclusions from this model to be drawn.

264 As described above, crystalloids are less effective (25\%) due to fluid dispersion into the 265 interstitium $(7,46)$. Zaar et al. presented the consequences of hemodilution and demonstrated 266 exacerbated liver bleeding following HES administration, whereas crystalloids mitigated the effect 267 (46). Other studies have claimed that colloids affect coagulation by themselves $(40,47)$. We 268 observed similar results in our study directly after fluid resuscitation. However, intergroup 269 differences were temporally limited, as hemoglobin content and hematocrit remained unchanged 270 after four hours. Hemodilution reasonably explains coagulation deterioration directly following 271 fluid resuscitation, but not its long-term effects. Several mechanisms have been described to 272 explain this coagulopathy through colloids, including the negative influences of factor VIII (28), 273 factor XIII, fibrinolysis (29), the von Willebrand factor (30) and surface receptor GPIIb/IIIa on 274 platelets (31). Administration of HES can particularly trigger these effects, which are pronounced 275 by different types of HES. In this context, negative side effects of the new HES generation $276(130 / 0.4)$ are less relevant than those of older ones (e.g. HES 200/0.5), in which coagulation is 277 impaired to a higher degree (27). Mauch et al. reported on reduced fibrin polymerization, which 
278 depends on decreased factor XIII activity for restricted clot firmness $(40,47)$. This corresponds 279 with our thromboelastometry results, including the decreases in MCF, which can be interpreted as 280 a sign of impaired fibrin cross-linking in the colloid groups (e.g. Figure 3) (29). We also detected 281 further decreases in CT and alpha-angle as an indication of impaired clot development related to 282 factor VIII and the von Willebrand factor. These results are in line with Haas et al., who reported 283 compromised clot firmness following HES administration compared to GP in pigs (33). This effect 284 appears to be dose-dependent (32). Furthermore, the direct influence of HES on thrombocyte 285 function, which impairs rolling and adhesion capabilities, restricts GPIIb/IIIa receptor binding and 286 direct degeneration through increased osmotic pressure $(29,31)$. In theory, an effect of colloids on 287 fibrinolysis is possible, but we did not detect any signs of hyperfibrinolysis. Lower degrees of 288 hyperfibrinolysis may exceed the detection ability of a rotational thromboelastometry assay. The 289 minor sensitivity to detect beginning hyperfibrinolysis and the time consuming analysis is a relevant limitation in emergency situations (48). As another item of our study, we compared the measured porcine baseline values with standard parameters for human assays. We demonstrated that human assessments are suitable for this kind of research and generate useful values with general increased porcine coagulation (Table 2) (39). This might also help to established regimes for fluid resuscitation that can used likewise in veterinary medicine, where the number of relevant 295 studies is limited $(33,49)$.

296 In recent years, use of gelatine-based colloids has increased due to the unclear status of HES. 297 However, beneath the risk of anaphylaxis and kidney injury, evidence concerning the risk profile 298 of GP remains scarce $(24,50)$. Fast and effective therapy for hemorrhagic shock is indispensable. 299 Even if the bleeding is controlled, regeneration of adequate cardio-circulatory functions and 300 microcircular perfusion is essential to secure sufficient organ supply. If control of the bleeding is 301 not possible and blood products are not immediately available, fluid resuscitation under permissive 302 hypotension is inevitable (51). We designed our model according to a clinical scenario in which 303 immediate fluid resuscitation is considered lifesaving (52). This study demonstrated that the effect 304 of different infusion regimes and their potential consequences on coagulation are relevant even 305 after several hours. Especially, this long-term effect was an essential key finding of this study: 306 coagulopathy following colloid administration is not only a temporary phenomenon, but traceable 307 for hours after bleeding control and hemodynamic stabilization, but may become crucial with re308 occurrence of blood loss or demand for further surgery (33). In this context, we found a partial 
309 recovery four hours after the initial event, which suggests time-dependent progress. On the other

310 hand, experimental factors and the sub-project character limited to address these effects over an

311 even longer time interval to examine full spontaneous recovery. Additionally, we did not

312 retransfuse the removed blood to simulate an early phase without the availability of blood products

313 and assess the mere effects of the different colloids. In this context, specific thrombocyte function

314 analysis or extended coagulation factor determination could deliver additional findings.

315 Regrettably, these were not available for this study. Finally, the comparability of porcine to human

316 physiology allowed for a realistic clinical-like scenario in this study. Notably, however, several

317 physiological differences exist concerning lower hemoglobin content and hypercoagulation in

318 pigs, which must be considered with respect to translational research.

319 Conclusion: In a porcine hemorrhagic shock model HES, GP, but also standard BES sufficiently

320 stabilized the macrocirculation, but significantly affected coagulation. These effects are most

321 pronounced after colloid and particularly HES administration. The choice of solution in fluid

322 resuscitation affects coagulation, may exacerbate bleeding situation and therefore increase

323 patient's risk. Colloids have to be chosen with caution, because their molecular properties may

324 affect coagulation directly and as a consequence of pronounced hemodilution.

325

\section{Abbreviations}

327 GP: gelatine-polysuccinate; HES: hydroxyethyl starch; BES: balanced electrolyte solution;

328 PiCCO: pulse contour cardiac output system; SD: standard deviation; ANOVA: analysis of 329 variance; PTT: activated partial thromboplastin time; PT: prothrombin time; ROTEM: rotational 330 thromboelastometry; CT: clotting time; CFT: clot formation time, alpha; alpha-angle; A10: 331 amplitude 10; A20: amplitude 20; MCF: maximum clot firmness; MCL: maximum clot lysis; HR:

332 heart rate; MAP: mean arterial pressure; CI: cardiac index; Hb: hemoglobin content; Hct:

333 hematocrit; CI: cardiac index

\section{Availability of data and materials}

335 All data relevant to the study are included in this published article. This study belongs to a larger 336 research project that is investigated the effect of different solutions for fluid resuscitation on

337 cerebral perfusion, which has not yet been analyzed or published. Further data sets analyzed during

338 the current study are available from the corresponding author upon reasonable request. 


\section{Funding}

341 The study was funded by the German Research Foundation (DFG) ZI 1632/2-1 and Mainz

342 Research School of Translational Biomedicine (TransMed) fellowship affiliated with the Johannes

343 Gutenberg University, Mainz, Germany.

344

345 Keywords: gelatine-polysuccinate, hydroxyethyl starch, hemorrhagic shock, thromboelastometry,

346 pig model, comparison of porcine and human coagulation

347

348 Authors' contributions

349 EKH, AZ and AGB designed the study. AZ, CM, RR, JK and AGB conducted the study. CM and

350 MS analyzed the data, which were interpreted by AZ, EKH and ST. AZ, RR and EKH performed

351 the literature review and wrote the manuscript. CM, AGB, JK and ST proofread and revised the

352 manuscript. All authors read and approved the final manuscript. The manuscript was edited by

353 Scribendi editing service.

354

355 Competing interests

356 The authors have no competing interests to declare.

357

358 Consent for publication

359 Not applicable.

360

361 Ethics approval and consent to participate

362 This study was conducted after approval by the State and Institutional Animal Care Committee

363 (Landesuntersuchungsamt Rheinland-Pfalz, Mainzer Straße 112, 56068 Koblenz, Germany;

364 Chairperson: Dr Silvia Eisch-Wolf; reference number: 23 177-07/G 15-1-092; 01/2016).

365

366

367

368 Acknowledgements

369 The study is part of the $\mathrm{PhD}$ thesis of Alexander Ziebart. The authors thank Dagmar Dirvonskis

370 for her excellent technical assistance. 


\section{Presentation}

373 Preliminary data were presented as a poster presentation at the German Anesthesia Congress

374 (DAC) in April 2017 in Nurnberg, Germany, and the annual meeting of the American Society of

375 Anesthesiologists (ASA) in October 2019 in Orlando, USA.

376

377 1. Kutcher ME, Kornblith LZ, Narayan R, Curd V, Daley AT, Redick BJ, Nelson MF, Fiebig EW, Cohen

378 MJ. A paradigm shift in trauma resuscitation: evaluation of evolving massive transfusion practices. JAMA 379 surgery. 2013;148(9):834-40.

380 2. Noll E, Diana M, Charles AL, Singh F, Gan TJ, Pottecher J, Moussallieh FM, Namer IJ, Geny B, 381 Diemunsch P. Comparative analysis of resuscitation using human serum albumin and crystalloids or 382 130/0.4 hydroxyethyl starch and crystalloids on skeletal muscle metabolic profile during experimental 383 haemorrhagic shock in swine: A randomised experimental study. Eur J Anaesthesiol. 2017;34(2):89-97.

3843 3. Nielsen TK, Hvas CL, Dobson GP, Tonnesen E, Granfeldt A. Pulmonary function after hemorrhagic 385 shock and resuscitation in a porcine model. Acta Anaesthesiol Scand. 2014;58(8):1015-24.

386 4. Dubniks M, Persson J, Grande PO. Comparison of the plasma volume-expanding effects of $6 \%$ 387 dextran 70, 5\% albumin, and 6\% HES 130/0.4 after hemorrhage in the guinea pig. The Journal of trauma. 388 2009;67(6):1200-4.

389 5. Kozek-Langenecker SA, Afshari A, Albaladejo P, Santullano CA, De Robertis E, Filipescu DC, Fries

390 D, Gorlinger K, Haas T, Imberger G, Jacob M, Lance M, Llau J, Mallett S, Meier J, Rahe-Meyer N, Samama CM, Smith A, Solomon C, Van der Linden P, Wikkelso AJ, Wouters P, Wyffels P. Management of severe perioperative bleeding: guidelines from the European Society of Anaesthesiology. European journal of anaesthesiology. 2013;30(6):270-382.

394 6. Spahn DR, Bouillon B, Cerny V, Duranteau J, Filipescu D, Hunt BJ, Komadina R, Maegele M, Nardi G, Riddez L, Samama CM, Vincent JL, Rossaint R. The European guideline on management of major bleeding and coagulopathy following trauma: fifth edition. Critical care (London, England). 2019;23(1):98.

398 7. Orbegozo Cortes D, Gamarano Barros T, Njimi H, Vincent JL. Crystalloids versus colloids:

399 exploring differences in fluid requirements by systematic review and meta-regression. Anesthesia and 400 analgesia. 2015;120(2):389-402.

401 8. Guidet B, Martinet O, Boulain T, Philippart F, Poussel JF, Maizel J, Forceville X, Feissel M, 402 Hasselmann M, Heininger A, Van Aken H. Assessment of hemodynamic efficacy and safety of $6 \%$ 403 hydroxyethylstarch $130 / 0.4$ vs. $0.9 \% \mathrm{NaCl}$ fluid replacement in patients with severe sepsis: the 404 CRYSTMAS study. Critical care (London, England). 2012;16(3):R94.

405 9. Brunkhorst FM, Engel C, Bloos F, Meier-Hellmann A, Ragaller M, Weiler N, Moerer O, Gruendling 406 M, Oppert M, Grond S, Olthoff D, Jaschinski U, John S, Rossaint R, Welte T, Schaefer M, Kern P, Kuhnt E, 407 Kiehntopf M, Hartog C, Natanson C, Loeffler M, Reinhart K. Intensive insulin therapy and pentastarch 408 resuscitation in severe sepsis. N Engl J Med. 2008;358(2):125-39.

409 10. Perner A, Haase N, Guttormsen AB, Tenhunen J, Klemenzson G, Aneman A, Madsen KR, Moller $410 \mathrm{MH}$, Elkjaer JM, Poulsen LM, Bendtsen A, Winding R, Steensen M, Berezowicz P, Soe-Jensen P, Bestle M, 411 Strand K, Wiis J, White JO, Thornberg KJ, Quist L, Nielsen J, Andersen LH, Holst LB, Thormar K, 412 Kjaeldgaard AL, Fabritius ML, Mondrup F, Pott FC, Moller TP, Winkel P, Wetterslev J. Hydroxyethyl starch 413 130/0.42 versus Ringer's acetate in severe sepsis. N Engl J Med. 2012;367(2):124-34.

414 11. Annane D, Siami S, Jaber S, Martin C, Elatrous S, Declere AD, Preiser JC, Outin H, Troche G, 415 Charpentier C, Trouillet JL, Kimmoun A, Forceville X, Darmon M, Lesur O, Reignier J, Abroug F, Berger P, 
416 Clec'h C, Cousson J, Thibault L, Chevret S. Effects of fluid resuscitation with colloids vs crystalloids on

417 mortality in critically ill patients presenting with hypovolemic shock: the CRISTAL randomized trial. Jama.

418 2013;310(17):1809-17.

419 12. Dellinger RP, Levy MM, Rhodes A, Annane D, Gerlach H, Opal SM, Sevransky JE, Sprung CL, 420 Douglas IS, Jaeschke R, Osborn TM, Nunnally ME, Townsend SR, Reinhart K, Kleinpell RM, Angus DC, 421 Deutschman CS, Machado FR, Rubenfeld GD, Webb S, Beale RJ, Vincent JL, Moreno R, Surviving Sepsis 422 Campaign Guidelines Committee including The Pediatric S. Surviving Sepsis Campaign: international 423 guidelines for management of severe sepsis and septic shock, 2012. Intensive Care Med.

424 2013;39(2):165-228.

425 13. Myburgh JA, Finfer S, Bellomo R, Billot L, Cass A, Gattas D, Glass P, Lipman J, Liu B, McArthur C, 426 McGuinness S, Rajbhandari D, Taylor CB, Webb SA. Hydroxyethyl starch or saline for fluid resuscitation 427 in intensive care. N Engl J Med. 2012;367(20):1901-11.

428 14. Ferreira DA, Cruz R, Venancio C, Faustino-Rocha Al, Silva A, Mesquita JR, Ortiz AL, Vala H.

429 Evaluation of renal injury caused by acute volume replacement with Hydroxyethyl Starch 130/0.4 or

430 Ringer's lactate solution in pigs. Journal of veterinary science. 2018.

431 15. Rehm M, Hulde N, Kammerer T, Meidert AS, Hofmann-Kiefer K. State of the art in fluid and 432 volume therapy : A user-friendly staged concept. English version. Der Anaesthesist. 2019;68(Suppl 1):1-

43314.

434 16. Gillies MA, Habicher M, Jhanji S, Sander M, Mythen M, Hamilton M, Pearse RM. Incidence of 435 postoperative death and acute kidney injury associated with i.v. $6 \%$ hydroxyethyl starch use: systematic 436 review and meta-analysis. British journal of anaesthesia. 2014;112(1):25-34.

437 17. EMA. Hydroxyethyl starch solutions: CMDh introduces new measures to protect patients. 438 European Medicines Agency; 2018.

439 18. Beyer R, Harmening U, Rittmeyer O, Zielmann S, Mielck F, Kazmaier S, Kettler D. Use of modified 440 fluid gelatin and hydroxyethyl starch for colloidal volume replacement in major orthopaedic surgery. 441 British journal of anaesthesia. 1997;78(1):44-50.

442 19. Awad S, Dharmavaram S, Wearn CS, Dube MG, Lobo DN. Effects of an intraoperative infusion of 443

444 $4 \%$ succinylated gelatine (Gelofusine(R)) and $6 \%$ hydroxyethyl starch (Voluven(R)) on blood volume. British journal of anaesthesia. 2012;109(2):168-76.

446 20. Qureshi SH, Rizvi SI, Patel NN, Murphy GJ. Meta-analysis of colloids versus crystalloids in critically ill, trauma and surgical patients. Br J Surg. 2016;103(1):14-26.

447 21. National Clinical Guideline C. National Institute for Health and Clinical Excellence: Guidance. 448 Intravenous Fluid Therapy: Intravenous Fluid Therapy in Adults in Hospital. London: Royal College of 449 Physicians (UK)

450 National Clinical Guideline Centre.; 2013.

451 22. Wu CY, Chan KC, Cheng YJ, Yeh YC, Chien CT. Effects of different types of fluid resuscitation for 452 hemorrhagic shock on splanchnic organ microcirculation and renal reactive oxygen species formation. Critical care (London, England). 2015;19:434.

454 23. Witt L, Glage S, Lichtinghagen R, Pape L, Boethig D, Dennhardt N, Heiderich S, Leffler A, 455 Sumpelmann R. Impact of high doses of $6 \%$ hydroxyethyl starch $130 / 0.42$ and $4 \%$ gelatin on renal 456 function in a pediatric animal model. Paediatric anaesthesia. 2016;26(3):259-65.

457 24. Moeller C, Fleischmann C, Thomas-Rueddel D, Vlasakov V, Rochwerg B, Theurer P, Gattinoni L, 458 Reinhart K, Hartog CS. How safe is gelatin? A systematic review and meta-analysis of gelatin-containing 459 plasma expanders vs crystalloids and albumin. Journal of critical care. 2016;35:75-83.

460 25. Ertmer C, Rehberg S, Van Aken H, Westphal M. Relevance of non-albumin colloids in intensive 461 care medicine. Best practice \& research Clinical anaesthesiology. 2009;23(2):193-212. 
462 26. Rasmussen KC, Secher NH, Pedersen T. Effect of perioperative crystalloid or colloid fluid therapy

463

464

465

466

467

468

469

470

471

472

473

474

475

476

477

478

479

480

481

482

483

484

485

486

487

488

489

490

491

492

493

494

495

496

497

498

499

500

501

502

503

504

505

506

507

508

509

on hemorrhage, coagulation competence, and outcome: A systematic review and stratified metaanalysis. Medicine. 2016;95(31):e4498.

27. Entholzner EK, Mielke LL, Calatzis AN, Feyh J, Hipp R, Hargasser SR. Coagulation effects of a recently developed hydroxyethyl starch (HES 130/0.4) compared to hydroxyethyl starches with higher molecular weight. Acta anaesthesiologica Scandinavica. 2000;44(9):1116-21.

28. Stump DC, Strauss RG, Henriksen RA, Petersen RE, Saunders R. Effects of hydroxyethyl starch on blood coagulation, particularly factor VIII. Transfusion. 1985;25(4):349-54.

29. Reuteler A, Axiak-Flammer S, Howard J, Adamik KN. Comparison of the effects of a balanced crystalloid-based and a saline-based tetrastarch solution on canine whole blood coagulation and platelet function. Journal of veterinary emergency and critical care (San Antonio, Tex : 2001). 2017;27(1):23-34. 30. Sanfelippo MJ, Suberviola PD, Geimer NF. Development of a von Willebrand-like syndrome after prolonged use of hydroxyethyl starch. American journal of clinical pathology. 1987;88(5):653-5.

31. Treib J, Haass A, Pindur G, Treib W, Wenzel E, Schimrigk K. Influence of intravascular molecular weight of hydroxyethyl starch on platelets. European journal of haematology. 1996;56(3):168-72.

32. Witt L, Osthaus WA, Jahn W, Rahe-Meyer N, Hanke A, Schmidt F, Boehne M, Sumpelmann R. Isovolaemic hemodilution with gelatin and hydroxyethylstarch 130/0.42: effects on hemostasis in piglets. Paediatric anaesthesia. 2012;22(4):379-85.

33. Haas T, Fries D, Holz C, Innerhofer P, Streif W, Klingler A, Hanke A, Velik-Salchner C. Less impairment of hemostasis and reduced blood loss in pigs after resuscitation from hemorrhagic shock using the small-volume concept with hypertonic saline/hydroxyethyl starch as compared to administration of $4 \%$ gelatin or $6 \%$ hydroxyethyl starch solution. Anesth Analg. 2008;106(4):1078-86, table of contents.

34. Mittermayr M, Streif W, Haas T, Fries D, Velik-Salchner C, Klingler A, Oswald E, Bach C, SchnapkaKoepf M, Innerhofer P. Hemostatic changes after crystalloid or colloid fluid administration during major orthopedic surgery: the role of fibrinogen administration. Anesthesia and analgesia. 2007;105(4):905-17, table of contents.

35. Durila M, Jonas J, Durilova M, Rygl M, Skrivan J, Vymazal T. Thromboelastometry as an Alternative Method for Coagulation Assessment in Pediatric Patients Undergoing Invasive Procedures: A Pilot Study. European journal of pediatric surgery : official journal of Austrian Association of Pediatric Surgery $[$ et al] = Zeitschrift fur Kinderchirurgie. 2018.

36. Tanczos K, Nemeth M, Molnar Z. What's new in hemorrhagic shock? Intensive care medicine. 2015;41(4):712-4.

37. Ziebart A, Mollmann C, Garcia-Bardon A, Kamuf J, Schafer M, Thomas R, Hartmann EK. Effect of gelatin-polysuccinat on cerebral oxygenation and microcirculation in a porcine haemorrhagic shock model. Scandinavian journal of trauma, resuscitation and emergency medicine. 2018;26(1):15.

38. Ziebart A, Kamuf J, Ruemmler R, Rissel R, Gosling M, Garcia-Bardon A, Hartmann EK. Standardized Hemorrhagic Shock Induction Guided by Cerebral Oximetry and Extended Hemodynamic Monitoring in Pigs. Journal of visualized experiments : JoVE. 2019(147).

39. Lang T, Bauters A, Braun SL, Potzsch B, von Pape KW, Kolde HJ, Lakner M. Multi-centre investigation on reference ranges for ROTEM thromboelastometry. Blood coagulation \& fibrinolysis : an international journal in haemostasis and thrombosis. 2005;16(4):301-10.

40. Mauch J, Madjdpour C, Kutter AP, Spielmann N, Bettschart-Wolfensberger R, Weiss M, Haas T. Effect of rapid fluid resuscitation using crystalloids or colloids on hemostasis in piglets. Paediatric anaesthesia. 2013;23(3):258-64.

41. Prat NJ, Meyer AD, Ingalls NK, Trichereau J, DuBose JJ, Cap AP. Rotational thromboelastometry significantly optimizes transfusion practices for damage control resuscitation in combat casualties. J Trauma Acute Care Surg. 2017;83(3):373-80.

Peer] reviewing PDF | (2019:09:41735:1:1:NEW 8 Dec 2019) 
510 42. Ziebart A, Möllmann C, Garcia-Bardon A, Kamuf J, Schäfer M, Thomas R, Hartmann EK. Effect of 511 gelatin-polysuccinat on cerebral oxygenation and microcirculation in a porcine haemorrhagic shock 512 model. Scandinavian journal of trauma, resuscitation and emergency medicine. 2018;26(1):15.

513 43. Ziebart A, Hartmann EK, Thomas R, Liu T, Duenges B, Schad A, Bodenstein M, Thal SC, David M. 514 Low tidal volume pressure support versus controlled ventilation in early experimental sepsis in pigs. 515 Respiratory research. 2014;15:101.

516 44. Lechner R, Helm M, Muller M, Wille T, Riesner HJ, Friemert B. In-vitro study of species-specific 517 coagulation differences in animals and humans using rotational thromboelastometry (ROTEM). J R Army 518 Med Corps. 2018.

519 45. Velik-Salchner C, Schnurer C, Fries D, Mussigang PR, Moser PL, Streif W, Kolbitsch C, Lorenz IH.

520 Normal values for thrombelastography (ROTEM) and selected coagulation parameters in porcine blood. 521 Thrombosis research. 2006;117(5):597-602.

522 46. Zaar M, Lauritzen B, Secher NH, Krantz T, Nielsen HB, Madsen PL, Johansson PI. Initial

523 administration of hydroxyethyl starch vs lactated Ringer after liver trauma in the pig. British Journal

524 Anaesthesia. 2009;102(2):221-6.

525 47. Dirkmann D, Hanke AA, Gorlinger K, Peters J. Hypothermia and acidosis synergistically impair 526 coagulation in human whole blood. Anesthesia and analgesia. 2008;106(6):1627-32.

527 48. Larsen OH, Fenger-Eriksen C, Ingerslev J, Sorensen B. Improved point-of-care identification of 528 hyperfibrinolysis is needed. Thrombosis research. 2012;130(4):690-1.

529 49. Wong C, Koenig A. The Colloid Controversy: Are Colloids Bad and What Are the Options? The

530 Veterinary clinics of North America Small animal practice. 2017;47(2):411-21.

531 50. Demir A, Aydinli B, Toprak HI, Karadeniz U, Yilmaz FM, Zungun C, Ucar P, Guclu CY, Bostanci EB,

532 Yilmaz S. Impact of 6\% Starch 130/0.4 and 4\% Gelatin Infusion on Kidney Function in Living-Donor Liver

533 Transplantation. Transplantation proceedings. 2015;47(6):1883-9.

534 51. Kalkwarf KJ, Cotton BA. Resuscitation for Hypovolemic Shock. The Surgical clinics of North 535 America. 2017;97(6):1307-21.

536 52. Ziebart A, Möllmann C, Garcia-Bardon A, Kamuf J, Schäfer M, Thomas R, Hartmann EK. Effect of 537 gelatin-polysuccinat on cerebral oxygenation and microcirculation in a porcine haemorrhagic shock model. Scandinavian Journal Trauma Resuscitation Emergency Medicin. 2018;26(1):15. 
Figure 1

Figure 1: Experimental flow chart

$\mathrm{GP}=$ gelatine-polysuccinate; HES = hydroxyethyl starch; BES = balanced electrolyte solution; $\mathrm{BLH}=$ baseline healthy

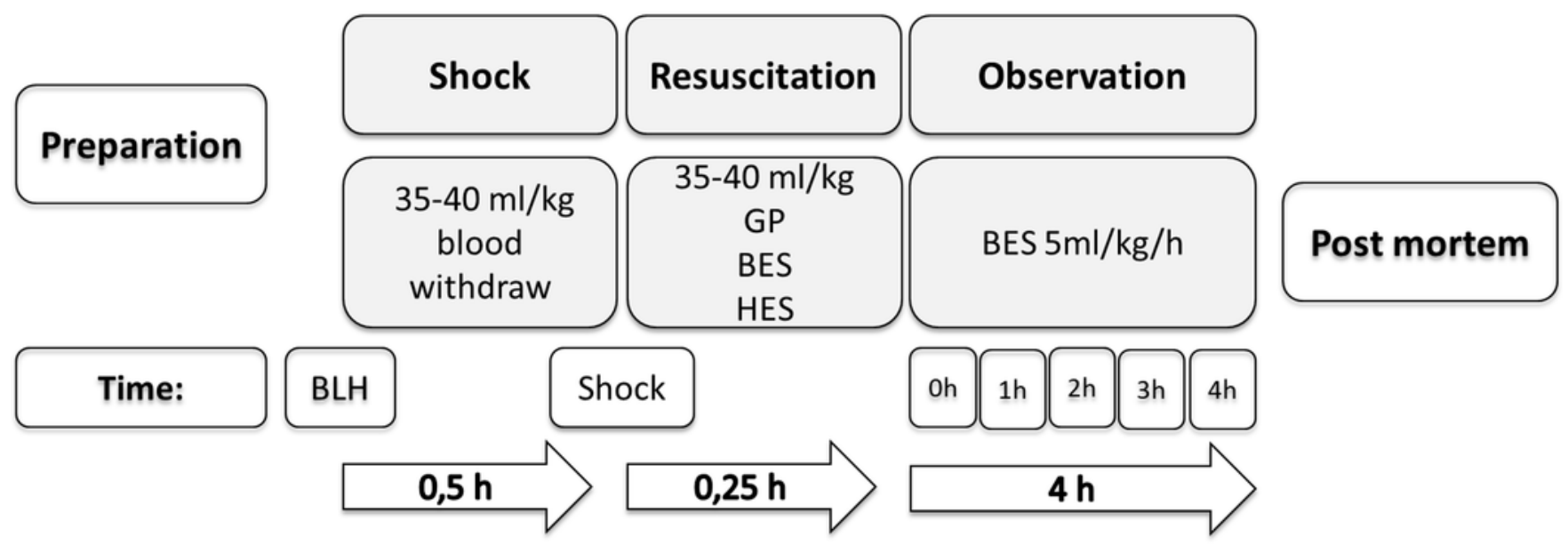




\section{Figure 2}

Figure 2: Laboratory coagulation parameters.

$\mathrm{A}=$ prothrombin time; $\mathrm{B}=$ activated partial thromboplastin time; $\mathrm{C}=$ platelet count $\mathrm{D}=$ fibrinogen

Group effects over time were analyzed using two-way ANOVA and the post-hoc Student-Newman-Keuls method.

$*=p<0.05$ timepoint comparison to the baseline ( $1=$ HES; $2=\mathrm{GP} ; 3=\mathrm{BES})$;

$\#=p<0.05$ in the intergroup comparison ( $1=$ HES vs. GP; $2=$ GP vs. BES; $3=$ HES vs. BES);

$\mathrm{GP}=$ gelatine-polysuccinate; $\mathrm{HES}$ = hydroxyethyl starch; $\mathrm{BES}$ = balanced electrolyte solution
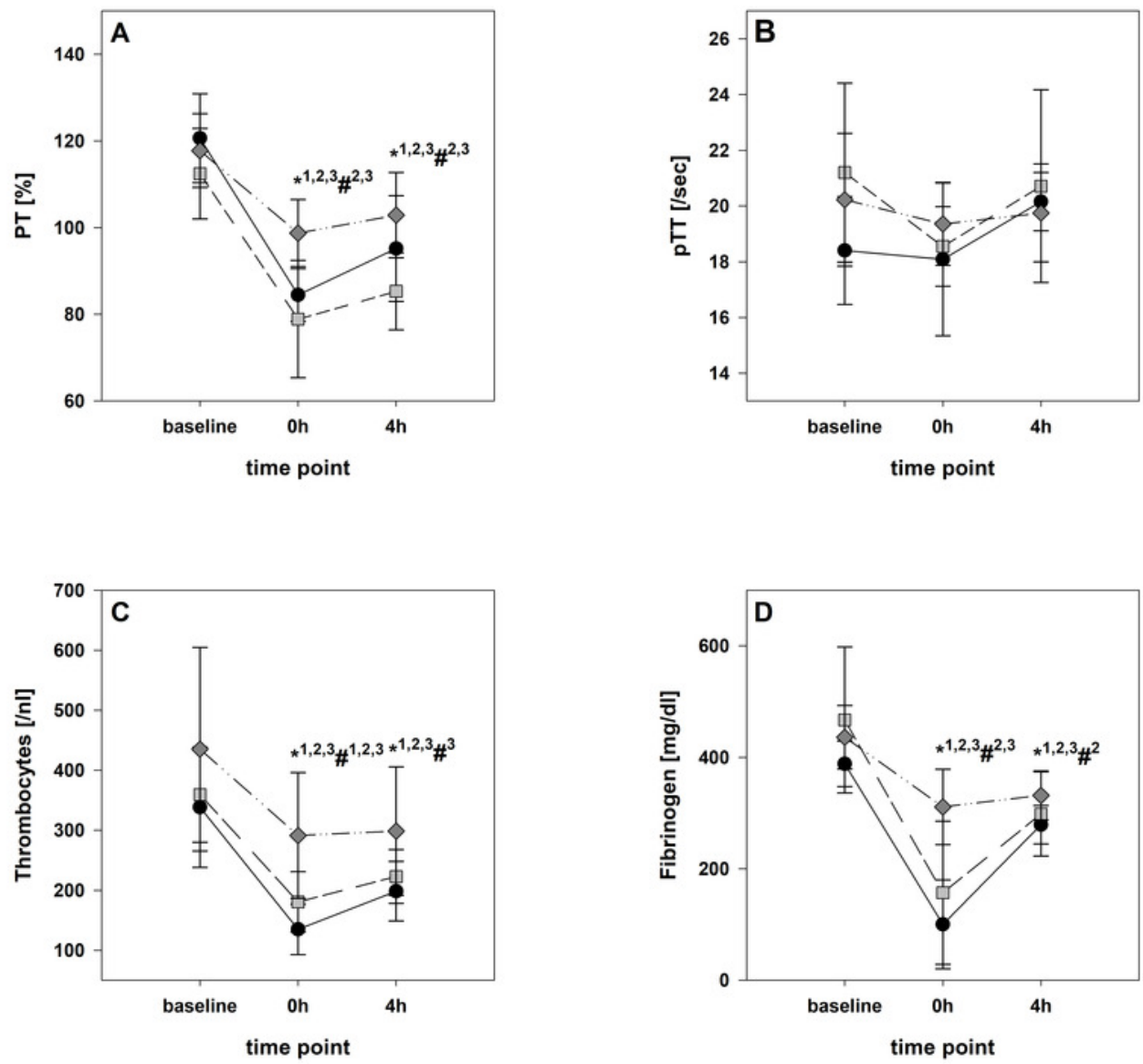
Figure 3

Figure 3: EXTEM (tissue factor pathway)

$\mathrm{A}=$ clotting time; $\mathrm{B}=$ clot formatting time; $\mathrm{C}=$ amplitude $20 ; \mathrm{D}=$ maximum clot firmness

Group effects over time were analyzed using two-way ANOVA and the post-hoc Student-Newman-Keuls method.

$*=p<0.05$ timepoint comparison to the baseline ( $1=$ HES; $2=\mathrm{GP} ; 3=\mathrm{BES})$;

$\#=p<0.05$ in the intergroup comparison ( $1=$ HES vs. GP; $2=$ GP vs. BES; $3=$ HES vs. BES);

$\mathrm{GP}=$ gelatine-polysuccinate; $\mathrm{HES}$ = hydroxyethyl starch; $\mathrm{BES}$ = balanced electrolyte solution

\section{EXTEM}
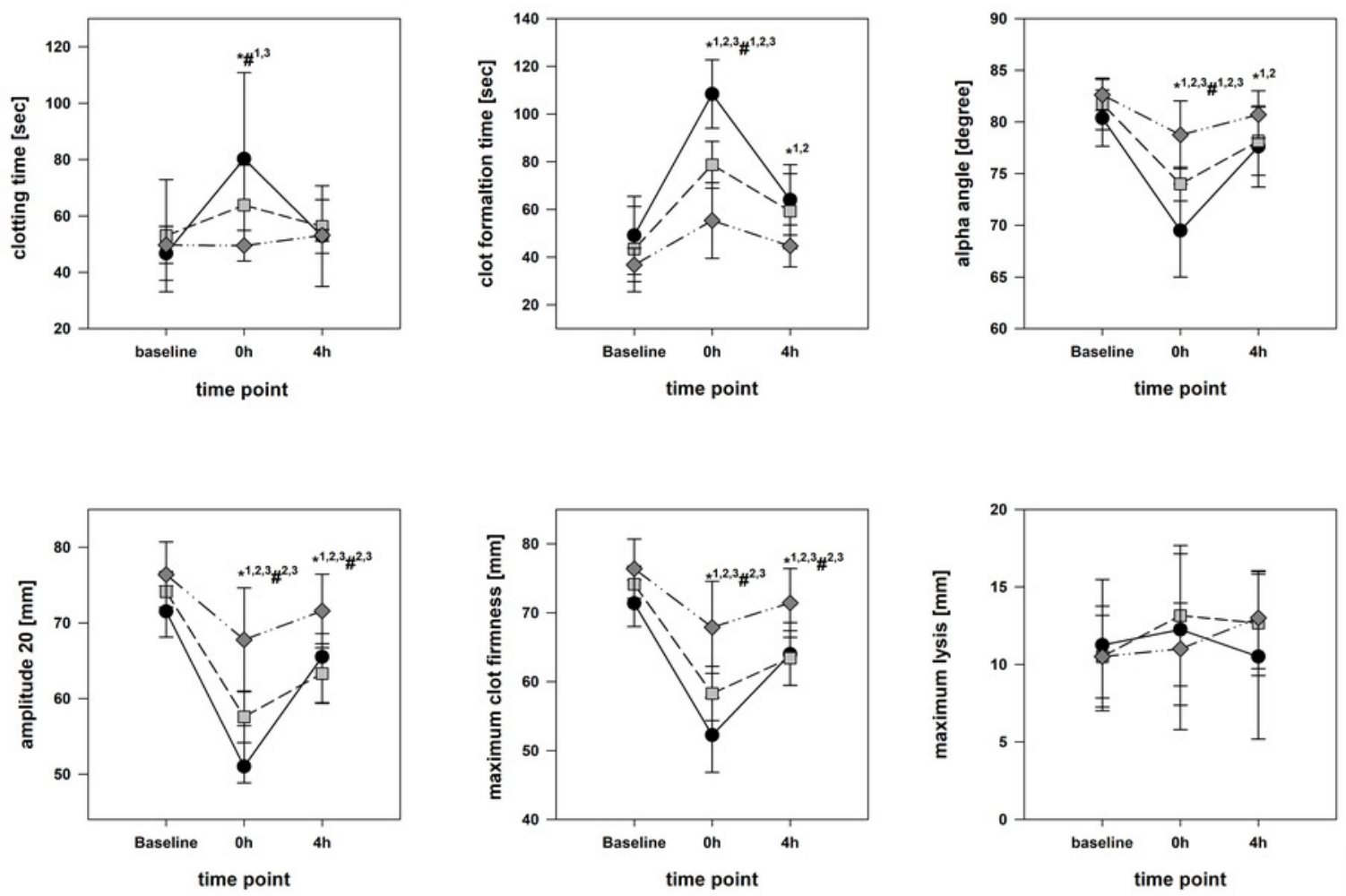
Figure 4

Figure 4: INTEM (contact activation pathway)

$A=$ clotting time; $B=$ clot formatting time; $C=$ amplitude $20 ; D=$ maximum clot firmness Group effects over time were analyzed using two-way ANOVA and the post-hoc Student-Newman-Keuls method.

$*=p<0.05$ timepoint comparison to the baseline $(1=\mathrm{HES} ; 2=\mathrm{GP} ; 3=\mathrm{BES})$;

$\#=p<0.05$ in the intergroup comparison ( $1=$ HES vs. GP; 2 = GP vs. BES; $3=$ HES vs. BES);

$\mathrm{GP}$ = gelatine-polysuccinate; HES = hydroxyethyl starch; $\mathrm{BES}=$ balanced electrolyte solution

INTEM
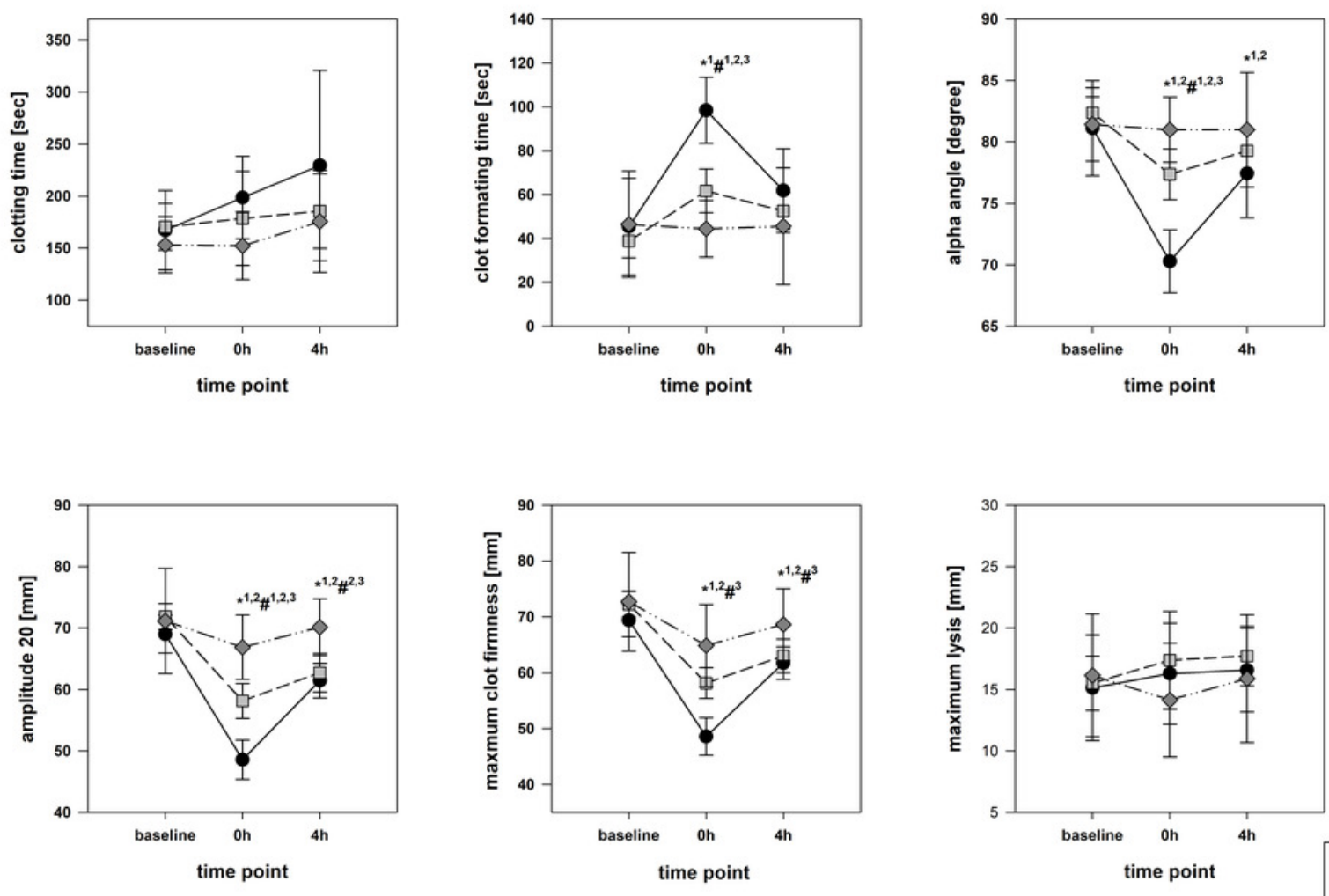

$\begin{array}{ll}\longrightarrow- & \text { HES } \\ ---\square-- & \text { GP } \\ -\cdots-\cdots & \text { BES }\end{array}$ 


\section{Figure 5}

Figure 5: FIBTEM-Test (fibrinogen deficiency detection)

$\mathrm{A}=$ clotting time; $\mathrm{B}=$ clot formatting time; $\mathrm{C}=$ amplitude $20 ; \mathrm{D}=$ maximum clot firmness

Group effects over time were analyzed using two-way ANOVA and the post-hoc Student-Newman-Keuls method.

$*=p<0.05$ timepoint comparison to the baseline $(1=\mathrm{HES} ; 2=\mathrm{GP} ; 3=\mathrm{BES})$;

$\#=p<0.05$ in the intergroup comparison ( $1=$ HES vs. GP; $2=$ GP vs. BES; $3=$ HES vs. BES);

$\mathrm{GP}=$ gelatine-polysuccinate; $\mathrm{HES}$ = hydroxyethyl starch; $\mathrm{BES}$ = balanced electrolyte solution

FIBTEM
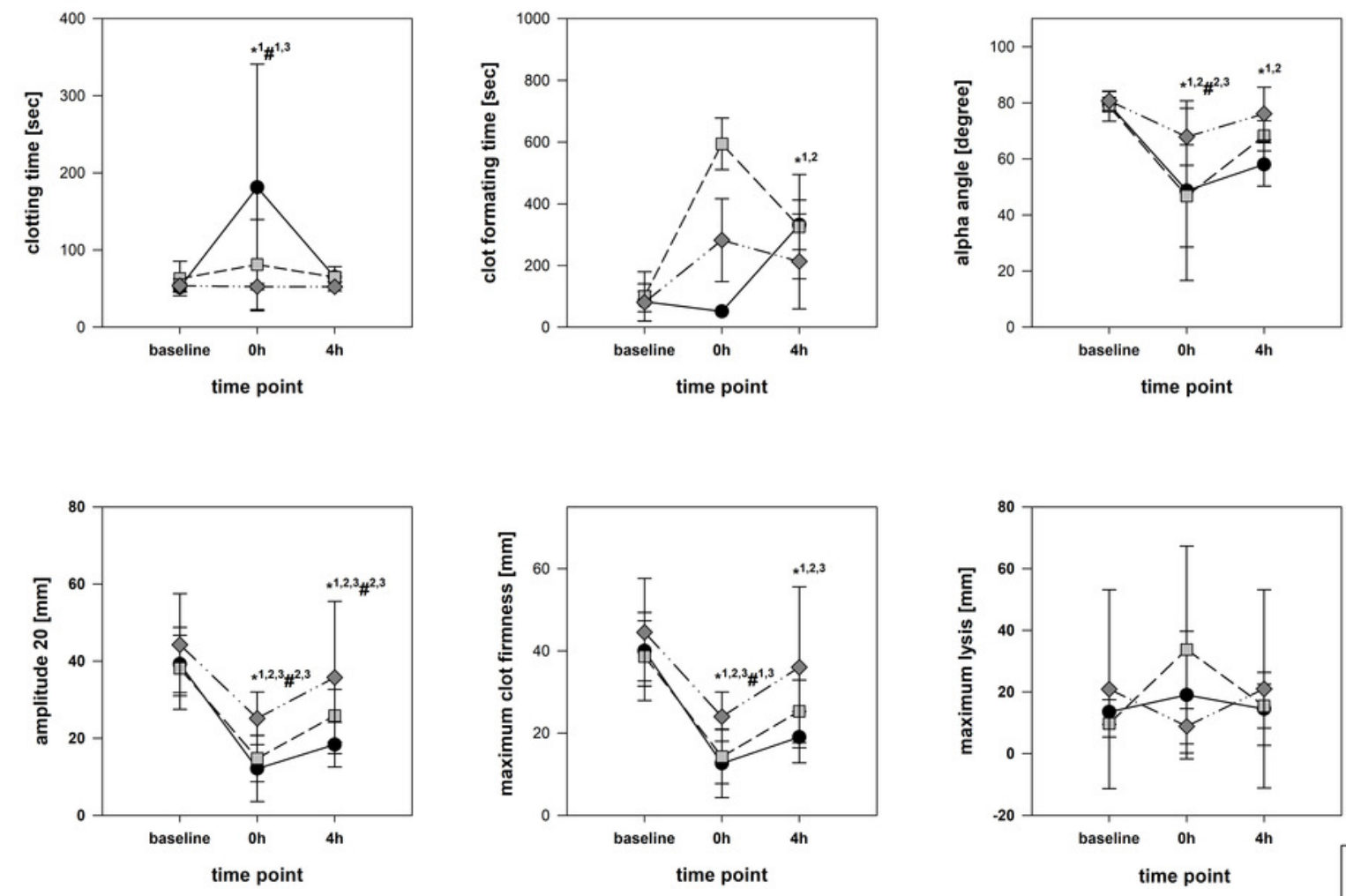
Figure 6

Figure 6: APTEM-Test (hyper-fibrinolysis-detection)

$\mathrm{A}=$ clotting time; $\mathrm{B}=$ clot formatting time; $\mathrm{C}=$ amplitude $20 ; \mathrm{D}=$ maximum clot firmness

Group effects over time were analyzed using two-way ANOVA and the post-hoc Student-Newman-Keuls method.

$*=p<0.05$ timepoint comparison to the baseline ( $1=$ HES; $2=\mathrm{GP} ; 3=\mathrm{BES})$;

$\#=p<0.05$ in the intergroup comparison ( $1=$ HES vs. GP; $2=$ GP vs. BES; $3=$ HES vs. BES);

$\mathrm{GP}=$ gelatine-polysuccinate; $\mathrm{HES}$ = hydroxyethyl starch; $\mathrm{BES}$ = balanced electrolyte solution

\section{APTEM}
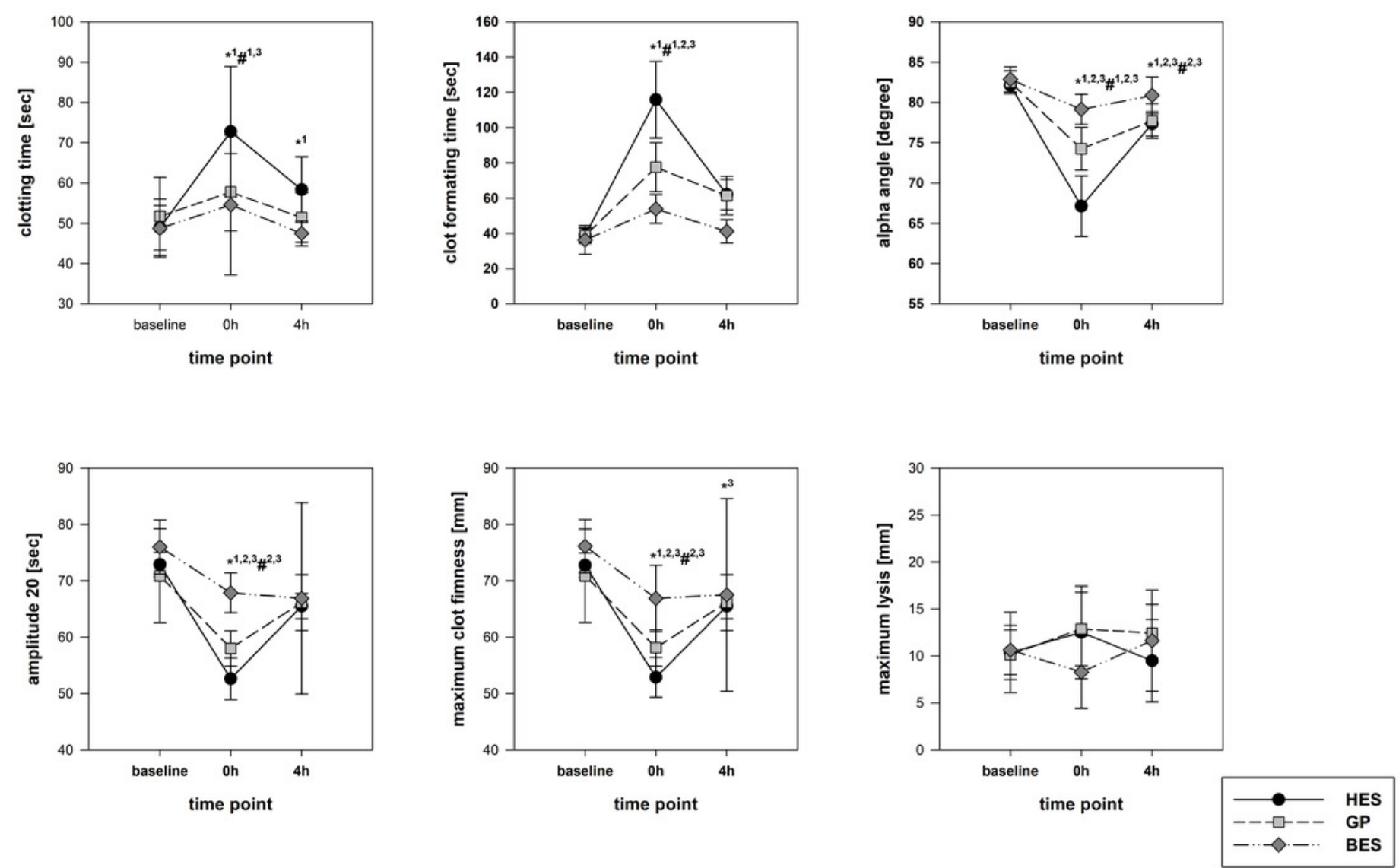


\section{Table $\mathbf{1}$ (on next page)}

Table 1: Extended hemodynamic and blood parameters

$*=$ indicates $p<0.05$ timepoint comparison to baseline;

$\#=$ indicates $p<0.05$ in intergroup comparison ( $1=$ HES vs. GP; $2=$ GP vs. BES; $3=$ HES vs. BES)

SD: Standard deviation; MAP: mean arterial pressure $(\mathrm{mmHg})$; HR: heart rate $\left(\mathrm{min}^{-1}\right)$; $\mathrm{Cl}$ : cardiac index $\left[\mathrm{l} / \mathrm{min} / \mathrm{m}^{2}\right] ; \mathrm{Hct}=$ Hematocrit $(\%) ; \mathrm{Hb}=$ Hemoglobin $(\mathrm{g} / \mathrm{dl})$ 


\begin{tabular}{|c|c|c|c|c|c|c|}
\hline $\begin{array}{l}\text { Parameter } \\
\text { Mean (SD) }\end{array}$ & & BLH & Shock & $\mathbf{0 h}$ & $2 \mathrm{~h}$ & $4 h$ \\
\hline \multirow{3}{*}{ MAP } & HES & $66(8)$ & $31(10)^{*}$ & $80(11)^{*}$ & $67(8)$ & $65(7)$ \\
\hline & GP & $70(9)$ & $25(5)^{*}$ & $76(16)$ & $59(10)^{*}$ & $61(6)^{*}$ \\
\hline & BES & $61(11)$ & $29(4)^{*}$ & $73(10)$ & $58(8)$ & $58(9)$ \\
\hline \multirow{3}{*}{ HR } & HES & $75(17)$ & $116(38)^{*}$ & $123(42)^{*}$ & $99(33)$ & $99(33)$ \\
\hline & GP & $84(10)$ & $145(53)^{*}$ & $137(26)^{*}$ & $106(27)$ & $104(21)$ \\
\hline & BES & $78(22)$ & $144(46)^{*}$ & $118(31)^{*}$ & $127(48)^{*}$ & $134(40)^{*}$ \\
\hline \multirow{3}{*}{ CI } & HES & $4.2(0.7)$ & $2.1(0.4)^{*}$ & $7.5(2.6)^{*} \#^{3}$ & $5.7(1.4)^{*}$ & $4.7(0.8)$ \\
\hline & GP & $4.8(1)$ & $2(0.3)^{*}$ & $7.6(2)^{*} \#^{2}$ & $5.4(1.3)$ & $5.6(1.6)$ \\
\hline & BES & $4.1(1.2)$ & $2.2(0.4)^{*}$ & $5.4(0.9)^{*} \# 2,3$ & $4.4(0.6)$ & $4.7(0.6)$ \\
\hline \multirow{3}{*}{ HCT } & HES & $26.6(2.5)$ & $23.2(1.7)$ & $13.4(2)^{*} \#^{3}$ & $16.1(3.2)^{*} \#^{3}$ & $17(2.1)^{*}$ \\
\hline & GP & $28.5(1.4)$ & $23(2.1)$ & $11,9(1,7)^{*} \#^{2}$ & $18.2(0.5)^{*} \#^{2}$ & $14.2(1.6)^{*}$ \\
\hline & BES & $26.1(2.3)$ & $23.6(2.5)$ & $17(1.8)^{*} \#^{2,3}$ & $19.6(1.4)^{*} \#^{2,3}$ & $16.8(1)^{*}$ \\
\hline \multirow{3}{*}{ HB } & HES & $8.6(0.8)$ & $7.5(0.5)$ & $4.8(0.8)^{*} \#^{3}$ & $5.1(0.7)^{*} \#^{3}$ & $5.1(0.6)^{*}$ \\
\hline & GP & $9.2(0.5)$ & $7.5(0.7)$ & $4.7(0.9)^{*} \#^{2}$ & $4.7(0.5)^{*} \#^{2}$ & $4.6(0.5)^{*}$ \\
\hline & BES & $8.5(0.7)$ & $7.7(0.8)$ & $5.9(0.3)^{*} \#^{2,3}$ & $5.4(0.3)^{*} \#^{2,3}$ & $5.4(0.3)^{*}$ \\
\hline
\end{tabular}




\section{Table 2 (on next page)}

Table 2: Comparison of human and porcine thromboelastometric references( $n=24)($ 37 )

Table 2: Comparison of human and porcine thromboelastometric references $(n=24)$ ( 37 ) Data are displayed in the $95 \%$ confidence interval of absolute values (AV) and in relation (R) (displayed in percentage) to human values. $\mathrm{CT}=$ clotting time (sec); $\mathrm{CFT}=$ clot formation time (sec); APLHA = alpha-angle (degree); A10 = amplitude 10\% (mm); A20 = amplitude 20\% $(\mathrm{mm}) ; \mathrm{MCF}=$ Maximum clot firmness $(\mathrm{mm}) ; \mathrm{ML}=$ maximum lysis $(\mathrm{mm})$ 


\begin{tabular}{|c|c|c|c|c|c|c|c|c|c|c|c|c|c|c|c|c|}
\hline \multirow{3}{*}{$\begin{array}{c}\text { TEST } \\
\text { SPECIES } \\
\text { UNIT }\end{array}$} & \multicolumn{4}{|c|}{ EXTEM } & \multicolumn{4}{|c|}{ INTEM } & \multicolumn{4}{|c|}{ FIBTEM } & \multicolumn{4}{|c|}{ AРТЕМ } \\
\hline & \multicolumn{2}{|c|}{ HUMAN } & \multicolumn{2}{|c|}{ PIG } & \multicolumn{2}{|c|}{ HUMAN } & \multicolumn{2}{|c|}{ PIG } & \multicolumn{2}{|c|}{ HUMAN } & \multicolumn{2}{|c|}{ PIG } & \multicolumn{2}{|c|}{ HUMAN } & \multicolumn{2}{|c|}{ PIG } \\
\hline & AV & $\mathrm{R}$ & $\mathrm{AV}$ & $\mathrm{R}$ & $\mathrm{AV}$ & $\mathrm{R}$ & AV & $\mathrm{R}$ & AV & $\mathrm{R}$ & $\mathrm{AV}$ & $\mathrm{R}$ & AV & $\mathrm{R}$ & AV & $\mathrm{R}$ \\
\hline CT & $42-74$ & 100 & $45-55$ & 86 & $137-246$ & 100 & $149-207$ & 93 & 43-69 & 100 & $50-62$ & 100 & $42-74$ & 100 & $47-53$ & 0 \\
\hline CFT & $46-148$ & 100 & $36-46$ & 42 & $42-100$ & 100 & $36-51$ & 61 & $46-148$ & 100 & $60-107$ & 86 & $46-148$ & 100 & $36-40$ & 39 \\
\hline ALPHA & $63-81$ & 100 & $81-83$ & 114 & $71-82$ & 100 & $81-83$ & 106 & $63-81$ & 100 & $78-81$ & 110 & $63-81$ & 100 & $82-83$ & 115 \\
\hline A10 & $43-65$ & 100 & $70-74$ & 133 & $44-68$ & 100 & $68-72$ & 125 & $9-24$ & 100 & $50-62$ & 339 & $43-65$ & 100 & $69-74$ & 132 \\
\hline A20 & $50-69$ & 100 & $72-76$ & 124 & $50-71$ & 100 & $69-73$ & 117 & $8-21$ & 100 & $36-45$ & 279 & $50-69$ & 100 & $71-76$ & 12 \\
\hline MCF & $49-71$ & 100 & $72-76$ & 123 & $52-72$ & 100 & $69-73$ & 115 & $9-25$ & 100 & $37-45$ & 241 & $49-71$ & 100 & $71-76$ & 12 \\
\hline ML & $0-18$ & 100 & $9-12$ & 117 & $0-12$ & 100 & $14-17$ & 258 & $13-27$ & 100 & $9-13$ & 55 & $0-18$ & 100 & $9-11$ & 11 \\
\hline
\end{tabular}

